\title{
Research on the Reform of Football Teaching in Chinese Colleges under the New Situation and Its Countermeasures
}

\author{
Xuejia Lu \\ Changchun Guanghua University, Changchun, Jilin, 130000
}

Keywords: Colleges, Football Training, Status Quo, Countermeasures.

\begin{abstract}
Since the beginning of the 21st century, with the quality of teaching system to promote and deepen the development of China's college football teaching syllabus has also been a corresponding reform, college sports teaching football curriculum is also constantly reform and development. At present, the college football teaching has gradually changed from the traditional teaching method to the diversified teaching method. In the teaching of football technology, it has also come out from the single teaching mode, and has gradually paid attention to the cultivation of the students' comprehensive quality. The overall development shows a good development trend. In addition, because of our long-term football teaching by traditional teaching methods, so to a certain extent, some college football teaching reform is still in place step by step. In this paper, the article analyzes the present situation of football teaching reform in our country under the current situation, and puts forward the effective reform measures. It is hoped that the reform of football teaching can be quick and smooth.
\end{abstract}

\section{Introduction}

With the number of college enrollment in recent years, the number of college students is more and more students love for football is not the same degree, but the impact of football on the students is huge, whether physical or psychological quality, are significant The meaning.

First of all, cultivate excellent physical fitness of college students. Football is a high-intensity, high-tech sports use project, it requires not only athletes have a strong physical quality, while requiring athletes and teammates between the good match and understanding. Therefore, football education can achieve the ability to exercise students in many aspects of quality. For example, students love football, want to join the ranks of football, we must have a good physical fitness, especially in the contemporary college students generally decline in physical condition, the cultivation of college students' physical quality is extremely important. Due to the popularity of the network, many college students in the school soon immersed in online games, which their physical and psychological have a great adverse impact, and through the cultivation of physical education, students can enjoy the play on the pitch, Through the perfect match between teammates, the formation of a strong sense of unity and psychological quality, for students after the life and work to lay a good foundation.

Second, the country to cultivate reserve football players. Colleges are a place where young people gather, but also a place where people gather, whether it is knowledge-based talent, or athletic talent, Colleges can always provide a number of useful talents for the country.

National football is a national football performance, the reason why China's football cause in the end of the ranks of the world, the main reason is that in Colleges did not form the popularity of football. Therefore, the college football education can also prepare for the country to prepare the football team. Football education in Colleges is not targeted to train students into football players, but by the popularity of football in Colleges, you can let the football in the country to get popular and enhance the football in the country's heat. At the same time, physical education teachers can find potential students to carry out specialized education for the national football career to provide 
reserve players.

\section{The Current Situation of College Football and the Problems}

Soccer the sport has been in the international development of a hundred years of history, during which the football culture, technology, knowledge, rules have been continuously improved. At present in our country college football teaching, although the students have a strong interest in football, but the students are not clear learning objectives, and their level of technical level, at the same time in the university

The average age of students is over 20 years old, which has missed the best time to learn soccer, so it is difficult for students to master the complex techniques of football and team tactics in limited learning time. In the teaching process of college football, teachers of football professors are generally still in the pilot teaching stage, which makes the atmosphere of the football classroom environment is poor, not very good

To mobilize the enthusiasm of students, so that college football teaching in the development process has been in a passive state, it caused a wide range of scholars concerned about the situation and a detailed analysis of the status quo.

Since the reform and opening up, China's college football has experienced more than 30 years of continuous development, has accumulated a certain success experience, but there are many headaches, such as: in the college sports teaching process, the teaching objectives Clearly, teachers in the course of teaching, usually only focus on football technology training, and often ignore the universal application of football; in the

In the syllabus of college football, the content of soccer sports in the curriculum arrangement on the proportion of the situation, so that students of football teaching part of the content is not interested, while the content of interest is very little; college football teaching too old-fashioned, no new elements, can not attract the attention of students; in college football teaching process, football teachers ignore the sense of students

Football teachers in the course of teaching, ignoring the development of their own characteristics, so that students in the learning process has been in a passive state, the arrangement and arrangement of teachers can not be very good; the teacher's teaching is not ideal; High understanding, resulting in students lack of learning initiative, affecting students to play personality; some football teachers of their own poor quality, ideas

In the old, the cultivation of the overall quality of the students did not attract attention; due to the constraints of the environment of the university, football teaching space is limited and the quality of failure, teaching equipment and teaching equipment is too old and simple, and quality problems.

\section{Solve the Problems of College Football Teaching Reform Measures}

College football in the content design is too single, should take full account of the students' own feelings, the current stage of college football teaching reform. At present, in the process of reform and innovation of college PE teaching quality education system, the football teaching classroom in our country is the key place to reflect the reform of PE teaching system. In recent years, many Colleges have not opened a football course for a long time, although the students can choose their own courses, but the football teaching curriculum does not follow the student's own psychological quality and students living environment to adjust the teaching methods, but in accordance with the traditional Teaching mode, the description of football technology is still step by step, the lack of reform and innovation, so that college football teaching system has not been able to get the hair

In the face of this problem, in addition to the original football teaching model to improve, but also on the football technical teaching activities to re-set, according to the student's own situation, targeted grouping, or by group Teaching, or according to the actual situation of different team members to classify teaching, and according to different teaching forms to prepare the appropriate teaching content, and assessment system, so that students in a pleasant and relaxed learning environment, actively into the football , The overall development of their own comprehensive 
quality.

To improve the teaching concept of college football, science for students to provide guidance for extracurricular activities, to develop students' sports spirit. From the overall teaching process of college sports, sports can be the perfect integration of human body and psychology, including: human purpose, knowledge, motivation, skills, needs, ideas, thinking patterns. At present, the college physical education is the key stage of cultivating students' own physical quality and cultivating good behavior habit. At this stage, it helps the students' physical development and cultivates the students' sports spirit. Therefore, the college football classroom teaching should be fully combined with the football itself has the health function and interesting, from the current stage of students love, love, like the growth of new things characteristics, the college football model of continuous reform and innovation, So that the classroom content of football to become full, wonderful, rich, in order to improve student interest in learning, to mobilize the students learning passion, so that students appreciate the study of football projects, no matter when and where will be the most comprehensive, The most effective and the most simple entertainment. In the future development of society, if not strong

Physical and long-term self-exercise of the spirit and ability, then the end will be the rapid development of social out, from this perspective, the physical integration of physical life and students, students can set a strong concept of sports, namely: Of the movement is the driving force of life. "

Concealment, the students will update the concept of mental health. In ancient times, in all mental health, mental health is the most important and indispensable, college football teaching content should be psychological factors into the health teaching, so that students consciously use football to achieve the purpose of exercise, To ensure a healthy mind and a good sense of health. The football teaching in Colleges can use the fighting spirit and the sense of competition in the football, and cultivate the tenacious and courageous and unyielding will make the psychological quality of the students become strong. In the teaching process of college football, students after jumping on the court, running, confrontation, competition, there will be a fun, free, unrestrained feeling, so that students will learn the daily life of the pressure and depressed release, so that Spirit is relieved and relaxed. A long time, students in the future fierce competition in the community can still maintain a relaxed optimism, positive, never give up the health of psychological quality, which the future development of students have a certain positive significance.

The school football teaching model is for reasonable arrangements, in accordance with the characteristics of the students themselves to start the classification of teaching, to strengthen the teaching of students as the main teaching philosophy. In the college football classroom teaching management concept, should strengthen the teaching of students as the main teaching ideas, in accordance with the characteristics of students to learn their own treatment, in the face of good sports quality of students, you can arrange some of the fierce, Competitive football game, so as to strengthen the skills of students to master the skills of football; the face of their own athletic students or students who are just beginning to learn, should have been taught to guide the main, you can arrange some interesting Sex football, while reducing the difficulty of teaching coefficient, so that students play in the process of football knowledge and skills to improve students' interest in learning football, so that students from the passive learning state turned to take the initiative to learn the state, In the process of continuous movement to enhance the awareness of sports, conscious exercise. The student-centered teaching model does not mean that students who are poor and inert to be accommodated are to live a student's teaching subject, and that they should adhere to the idea of health first and guide students to develop good habits through soccer, To strengthen their own health quality level.

Focus on the development of students' personality. In the traditional college football teaching mode, the teaching of football generally only focus on the cultivation of football technology, while ignoring the development of students' own personality, so in the future reform of football teaching to strengthen the student-oriented teaching concept, teachers Just to guide students to the idea. To guide students in the new teaching environment to actively ask questions, thinking, practice, and 
thus a more profound understanding of the principles of football, and to learn more about the principles of teaching, On this basis to master a set of their own technical action. Moreover, in the teaching process of college football, we should also fully penetrate the teaching content of moral knowledge, and guide students to respect the coaches, teachers, teammates, opponents, but also with the team spirit, mutual love, sensible, serious and responsible spirit. Teachers do not only teach but also educate the lofty realm, in order to meet the social needs of college students overall personality.

\section{Conclusion}

To sum up, health as a topic of concern since ancient times has been strongly advocated in the new situation, the college football teaching philosophy should also be placed in the content of teaching reform, teachers should be based on the students themselves Characteristics and physical and mental development trends of students, and strive for the further development of teaching reform to create favorable factors. At present, we should re-understand the college football classroom teaching objectives and tasks, and in the physical education syllabus to further planning adjustments. Students' interest in football is the key to building the concept of sports. In the course of football teaching, teachers not only to teach students the skills of football technology, but also pay attention to improving the overall quality of students. These are short-term can not be achieved in the future of college football reform and development of the road, but also need all teachers together, and strive to cultivate the new era of outstanding talent to contribute

\section{References}

[1] He Qingyong. Comparative Study of College Soccer and Professional Football in China [J]. Sports World, 009 (11)

[2] Guan Xuelui.Study on the practice of combining exercises and solving exercises in basketball teaching in ordinary Colleges [J]. Journal of Hebei Institute of Physical Education, 2005,31 (01): 76-79.

[3] Li Haijun. Experimental research on the reform of football teaching model in ordinary Colleges [J]. Journal of Lianyungang Teachers College, 2012, 19 (02): 59-62.

[4] Yuan Yutao, Tian Zhensheng, Zhang Mingjiang, Ma Jianlong.Experimental study on the implementation of target teaching in football class [J]. Journal of Agricultural University of Hebei, 2004, 12 (01): 81-83.

[5] Li Yijun, Kong Xiangping. Comparative analysis on the effect of Chinese and foreign women 's volleyball team in the 15th World Championship in 2006 [J]. Journal of Guangzhou Sport University, 2007 (4): 77- 79. 